\title{
Application of a Modified k-Means Algorithm to Evaluatesignificance of Bibliometric Indices of Journals
}

\author{
B. Annapurna \\ HoD, Computer Science \\ Ch.S.D.St. Theresa's College for \\ WomenAutonomous \\ Eluru, India
}

\author{
M. M. Naidu \\ R.V.R \&J.C.College of Engineering \\ Guntur \\ Andhra Pradesh \\ India
}

\begin{abstract}
The indices such as h-index, e-index etc has received much attention from the scientific community owing to their prowess to impact journal quality. Many different indicatorshave been developed to overcome drawbacks of hindex. Nearly four indices which are of prime importance in the publishing industry were utilized.In this paper, we present a modified k-means algorithm to generate three clusters of datasets of scientific journals.
\end{abstract}

\section{Keywords}

h-index, m-index, A-index, e-index, k-means algorithm

\section{INTRODUCTION}

The recent expansion of knowledge and increasingly sophisticated scientific techniques has led to a proliferation of journals in various fields of disciplines. There has been a progressive increase in the scientific methods of journal citation quantification. To assess the quality of publications in journals of scientific discipline, several authors proposed and delineated the purpose of bibliometric indices for journals. Bibliometrics of journals has become an important and a promising tool for authors to submit their research papers. Hence, impact factor proposed to assess the quality of journals, however, several controversies existed [1]. The journal impact factor developed by Eugene Garfield and published by the Thomson Reuters is the first bibliometric evaluator. However, the potentialities and several limitations of the impact factor have been well discussed [2] [3] [4] [5]. Alternative journal rankings [6] has been proposed, however, they deal with a small subset of the literature in any discipline.

In recent years, several research and publications related indices were proposed to assess the quality of the academic research publications. Each one of those indices has its own strengths and weaknesses. The knowledge of research indices started when Hirsh proposed the h-index, designed to measure the impact of research publications to estimate the author influence [7]. h-index has been regarded as the most reliable, robust and easily computed [8] [9] [10]. h-index assesses both the quantity and importance or relevance of publications [11]. h-index has some limitations, and hence to overcome and provide enhancements to $\mathrm{H}$-index, Egghe proposed the gindex [12]. Based on properties of $h$ and $g$ indices, Kosmulski [13] proposed the $\mathrm{H}(2)$-index which concentrates on highly cited research publications. Other indices were proposed which concentrated on the publications that were located at (H-core) in its calculations [14] such as A-index proposed by Jin [15] where, the average number of citations for those publications in the $\mathrm{H}$-core is evaluated. As a variation of Aindex, Bornmann etal proposed $\mathrm{m}$-index where, instead of arithmetic average, median is employed as the measure of central tendency [16]. m-index calculated by dividing the $h$ index by the number of years of that journal's publication [17]. In this paper, we propose a method which implements modified k-means clustering algorithm on a set of computer science journals for which indices are evaluated.

\section{MATERIALS AND METHODS}

\subsection{Dataset}

A dataset of 150 computer science journals were extracted from SCIMago [http://www.scimagojr.com/journalrank.php] website developed from the information contained in the Scopus database [18]. The parameters calculated by SCImago are Sci Journal Ranking (SJR), h-index, Total Docs, Total References, Total cites, citable docs, cites/doc and references/doc etc can be used to assess and analyze scientific domains.

\subsection{Python}

Using Python programming language, a program was written to perform k-means analysis. Python [19] has several advantages like open source, cross platform, object-oriented programming, dynamic typing features, simple and easy to learn and rich set of supporting libraries for mathematics, statistics, and visualization. Python modules like Numpy (Scientific Computing Tools for Python-Numpy), Scipy (Open Source Library of Scientific Tools), Python-Sklearn and matplotlib are used.

\subsection{Modified k-means algorithm}

A modification of k-means algorithm reported here, where, data scale to unit variance and principal component analysis used to reduce linear dimensionality using Singular Value Decomposition of the data or eigen value decomposition of a data covariance matrix and keeping only the most significant singular vectors to project the data to a lower dimensional space. A convergence criterion met until no new assignments appeared and until the centroids do not move significantly. If the dataset has more attributes, then each component represents one attribute and clustering will follow. Calculated inertia or within-cluster sum of squared criterion and clusters generated based on $\mathrm{k}$. In the next step, cluster quality metrics applied to judge the goodness of fit of the cluster such as homogeneity score, completeness score, V measure, adjusted rand score and silhouette coefficient.

\section{RESULTS AND DISCUSSION}

The first step in k-means algorithm is to divide the given data set into user defined number of clusters. The initial choice of $\mathrm{k}$ in $\mathrm{k}$-means is an interpretive decision and successive runs should be performed to obtain an optimized division of data for any chosen $\mathrm{k}$ value. A prior knowledge on the data structure would result in more appropriate clusters. However, 
as the dimensionality of the data increases, it becomes increasingly difficult to determine a proper value for $\mathrm{k}$. Hence, considerable attention has been given to the subject of cluster validation, a process which attempts to evaluate a particular division of data into clusters [20].

The outcome of modified k-means algorithm on a dataset of 150 journals resulted in 3 clusters $(\mathrm{k}=3)$. Each cluster data grouped based on the titles appeared in each group containing journal subjects such as Dataset 1 (Programming and Computing) Dataset 2(Data mining, knowledge discovery)Dataset 3(Information systems, Computing), respectively. Data was standardized and the output plot is given in Figure-1.

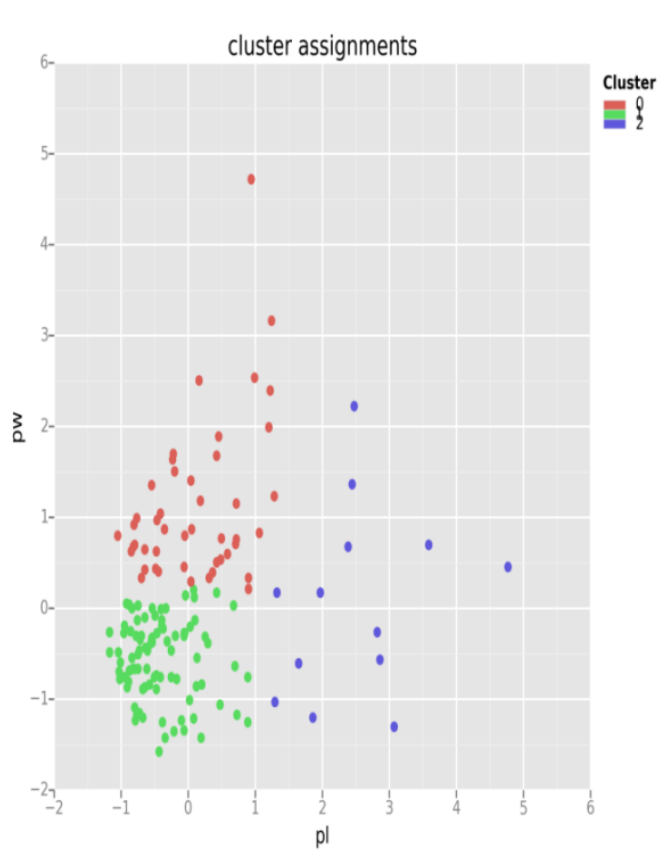

Figure 1: Cluster assignments of modified k-means clustering with $\mathbf{n}=\mathbf{3}$.

Quality of cluster validations is represented by homogeneity score, completeness score, $\mathrm{V}$ measure, adjusted rand score and silhouette coefficient. All these values are within the limits, given in Table-1.

Table 1: Validating the quality of clusters obtained from k-means

\begin{tabular}{|l|l|l|l|}
\hline Quality Metric & $\begin{array}{l}\text { Obtained value from } \\
\text { modified k-means, } \mathbf{n = 3}\end{array}$ & $\begin{array}{l}\text { Obtained value from } \\
\text { modified k-means, } \mathbf{n = 4}\end{array}$ & $\begin{array}{l}\text { Obtained value from } \\
\text { modified k-means, } \mathbf{n = 5}\end{array}$ \\
\hline Homogeneity score & 0.008 & 0.013 & 0.013 \\
\hline completeness score & 0.010 & 0.015 & 0.015 \\
\hline V measure & 0.009 & 0.014 & 0.014 \\
\hline Silhouette Coefficient & 0.452 & 0.266 & 0.353 \\
\hline
\end{tabular}

From the results it is observed that the modified k-means algorithm is able to generate clusters based on user input and the validation metrics reported in Table- 1 suggest that the scores of each metric with respect to $\mathrm{k}$ values are significant. A better Silhouette coefficient resulted in better clusters and hence $\mathrm{k}=3$ represents the best cluster.
Several indicators which assess the scientific merits of researchers reported in literature quantify both the number of published papers and their citations in various other journals. To some extent, some indicators rely on the citation of articles published in journals. Few such important indices are-index, h-index, A-index and m-index. The three datasets (Tables 2-4) were obtained from modified k-means algorithm.

Table 2: Dataset-1 with parameters and index values.

\begin{tabular}{|l|c|c|c|c|}
\hline Title & H index & e-index & A index & m index \\
\hline $\begin{array}{l}\text { Foundations and Trends in Computer Graphics and } \\
\text { Vision }\end{array}$ & 14 & 7 & 4.5 & 4.67 \\
\hline $\begin{array}{l}\text { IEEE Transactions on Pattern Analysis and Machine } \\
\text { Intelligence }\end{array}$ & 221 & 77.79 & 28.38 & 73.67 \\
\hline $\begin{array}{l}\text { Computer Methods in Applied Mechanics and } \\
\text { Engineering }\end{array}$ & 120 & 49.94 & 21.78 & 40 \\
\hline ACM Computing Surveys & 90 & 28.04 & 9.73 & 30 \\
\hline IEEE Transactions on Evolutionary Computation & 111 & 35.38 & 12.28 & 37 \\
\hline
\end{tabular}




\begin{tabular}{|c|c|c|c|c|}
\hline SIAM Journal on Computing & 68 & 19.54 & 6.62 & 22.67 \\
\hline Computers and Education & 77 & 60.39 & 48.36 & 25.67 \\
\hline Mathematical Programming & 75 & 24.39 & 8.93 & 25 \\
\hline $\begin{array}{l}\text { Proceedings - IEEE Symposium on Security and } \\
\text { Privacy }\end{array}$ & 43 & 24.19 & 14.6 & 14.33 \\
\hline ACM Transactions on Mathematical Software & 54 & 15.1 & 5.22 & 18 \\
\hline IEEE Transactions on Mobile Computing & 80 & 44.2 & 25.43 & 26.67 \\
\hline Computers and Geotechnics & 48 & 27.64 & 16.92 & 16 \\
\hline Journal of Machine Learning Research & 94 & 47.8 & 25.31 & 31.33 \\
\hline Foundations of Computational Mathematics & 29 & 13.23 & 7.03 & 9.67 \\
\hline Artificial Intelligence & 101 & 26.42 & 7.91 & 33.67 \\
\hline Computational Intelligence and Neuroscience & 23 & 19.9 & 18.22 & 7.67 \\
\hline Journal of Computer Assisted Learning & 48 & 20.9 & 10.1 & 16 \\
\hline $\begin{array}{l}\text { Proceedings of the Annual IEEE Conference on } \\
\text { Computational Complexity }\end{array}$ & 21 & 10.34 & 6.1 & 7 \\
\hline IEEE Computational Intelligence Magazine & 26 & 16.94 & 12.04 & 8.67 \\
\hline INFORMS Journal on Computing & 48 & 13.86 & 5 & 16 \\
\hline Statistics and Computing & 41 & 16.85 & 7.93 & 13.67 \\
\hline Journal of Scientific Computing & 42 & 23.9 & 14.6 & 14 \\
\hline $\begin{array}{l}\text { International Journal of Machine Learning and } \\
\text { Cybernetics }\end{array}$ & 15 & 17.75 & 22 & 5 \\
\hline IEEE/ASME Transactions on Mechatronics & 74 & 40.79 & 23.49 & 24.67 \\
\hline Automated Software Engineering & 29 & 10.1 & 4.52 & 9.67 \\
\hline Computational Geometry: Theory and Applications & 35 & 12.04 & 5.14 & 11.67 \\
\hline Journal of Graph Algorithms and Applications & 24 & 7.21 & 3.17 & 8 \\
\hline Advanced Engineering Informatics & 43 & 24.39 & 14.84 & 14.33 \\
\hline Artificial Intelligence and Law & 22 & 6.56 & 2.95 & 7.33 \\
\hline Theory and Practice of Logic Programming & 26 & 14 & 8.54 & 8.67 \\
\hline Fuzzy Optimization and Decision Making & 29 & 11 & 5.17 & 9.67 \\
\hline Computers and Mathematics with Applications & 69 & 74.37 & 81.16 & 23 \\
\hline Journal of Artificial Intelligence Research & 76 & 20.47 & 6.51 & 25.33 \\
\hline Mechanism and Machine Theory & 60 & 30.53 & 16.53 & 20 \\
\hline Empirical Software Engineering & 39 & 16.25 & 7.77 & 13 \\
\hline Algorithmica & 50 & 19.57 & 8.66 & 16.67 \\
\hline International Journal of Intelligent Systems & 46 & 20.42 & 10.07 & 15.33 \\
\hline $\begin{array}{l}\text { IEEE Transactions on Parallel and Distributed } \\
\text { Systems }\end{array}$ & 78 & 43.49 & 25.24 & 26 \\
\hline Control Engineering Practice & 67 & 36.12 & 20.48 & 22.33 \\
\hline Artificial Intelligence Review & 40 & 20.22 & 11.23 & 13.33 \\
\hline Mathematics of Control, Signals, and Systems & 26 & 6.08 & 2.42 & 8.67 \\
\hline $\begin{array}{l}\text { ACM Transactions on Software Engineering and } \\
\text { Methodology }\end{array}$ & 53 & 12.41 & 3.91 & 17.67 \\
\hline Engineering Applications of Artificial Intelligence & 54 & 35.81 & 24.74 & 18 \\
\hline Mathematical and Computer Modelling & 59 & 49.58 & 42.66 & 19.67 \\
\hline Integrated Computer-Aided Engineering & 25 & 17.38 & 13.08 & 8.33 \\
\hline Artificial Intelligence in Medicine & 53 & 19.31 & 8.04 & 17.67 \\
\hline Advances in Engineering Software & 39 & 26.85 & 19.49 & 13 \\
\hline
\end{tabular}


Table 3: Dataset-2 with parameters and index values.

\begin{tabular}{|c|c|c|c|c|}
\hline Title & e index & $\mathrm{H}$ index & A index & $m$ index \\
\hline Information Systems Research & 27.46 & 99 & 8.62 & 33 \\
\hline Journal of Operations Management & 28.43 & 108 & 8.48 & 36 \\
\hline IEEE Transactions on Fuzzy Systems & 48.66 & 119 & 20.9 & 39.67 \\
\hline International Journal of Robotics Research & 38.69 & 89 & 17.82 & 29.67 \\
\hline IEEE Transactions on Automatic Control & 72.63 & 175 & 31.14 & 58.33 \\
\hline Computers and Operations Research & 49.34 & 84 & 29.98 & 28 \\
\hline IEEE Transactions on Signal Processing & 88.86 & 162 & 49.74 & 54 \\
\hline IEEE Journal on Selected Topics in Signal Processing & 41.55 & 45 & 39.36 & 15 \\
\hline IEEE Transactions on Robotics & 42.05 & 77 & 23.96 & 25.67 \\
\hline IEEE Transactions on Image Processing & 74.72 & 169 & 34.04 & 56.33 \\
\hline Medical Image Analysis & 36.12 & 76 & 18.17 & 25.33 \\
\hline Computers and Structures & 37.5 & 75 & 19.75 & 25 \\
\hline ACM Transactions on Database Systems & 12.96 & 59 & 3.85 & 19.67 \\
\hline IEEE Signal Processing Magazine & 37.43 & 106 & 14.22 & 35.33 \\
\hline Journal of Field Robotics & 22.43 & 52 & 10.67 & 17.33 \\
\hline $\begin{array}{l}\text { IEEE Transactions on Knowledge and Data } \\
\text { Engineering }\end{array}$ & 41.89 & 103 & 18.04 & 34.33 \\
\hline Mechanical Systems and Signal Processing & 47.79 & 79 & 29.91 & 26.33 \\
\hline IEEE Transactions on Software Engineering & 29.75 & 111 & 8.97 & 37 \\
\hline IEEE Transactions on Neural Networks & 48.25 & 128 & 19.19 & 42.67 \\
\hline Pattern Recognition & 63.95 & 121 & 34.79 & 40.33 \\
\hline Machine Learning & 21.45 & 103 & 5.47 & 34.33 \\
\hline Journal of Computer and System Sciences & 21.95 & 56 & 9.61 & 18.67 \\
\hline $\begin{array}{l}\text { IEEE Transactions on Systems, Man, and } \\
\text { Cybernetics, Part B: Cybernetics }\end{array}$ & 49.31 & 102 & 24.83 & 34 \\
\hline Fuzzy Sets and Systems & 35.96 & 110 & 12.75 & 36.67 \\
\hline Data Mining and Knowledge Discovery & 18.76 & 62 & 6.68 & 20.67 \\
\hline $\begin{array}{l}\text { ACM Transactions on Information and System } \\
\text { Security }\end{array}$ & 13.86 & 41 & 5.68 & 13.67 \\
\hline Computational Statistics and Data Analysis & 34.47 & 57 & 21.84 & 19 \\
\hline Networks & 13.6 & 38 & 5.87 & 12.67 \\
\hline Mathematics of Operations Research & 12.04 & 50 & 3.9 & 16.67 \\
\hline IEEE Robotics and Automation Magazine & 22.54 & 51 & 10.96 & 17 \\
\hline Information and Computation & 15 & 50 & 5.5 & 16.67 \\
\hline Topics in Cognitive Science & 17.66 & 19 & 17.42 & 6.33 \\
\hline $\begin{array}{l}\text { ACM Transactions on Knowledge Discovery from } \\
\text { Data }\end{array}$ & 12.92 & 21 & 8.95 & 7 \\
\hline Robotics and Computer-Integrated Manufacturing & 27.15 & 51 & 15.45 & 17 \\
\hline Signal Processing & 51.38 & 77 & 35.29 & 25.67 \\
\hline Computational Geosciences & 17.94 & 34 & 10.47 & 11.33 \\
\hline IEEE Robotics and Automation Magazine & 22.54 & 51 & 10.96 & 17 \\
\hline Computational Materials Science & 55.98 & 59 & 54.12 & 19.67 \\
\hline $\begin{array}{l}\text { ACM Transactions on Knowledge Discovery from } \\
\text { Data }\end{array}$ & 12.92 & 21 & 8.95 & 7 \\
\hline IEEE Signal Processing Letters & 38.61 & 82 & 19.18 & 27.33 \\
\hline Pattern Recognition Letters & 46.7 & 92 & 24.71 & 30.67 \\
\hline
\end{tabular}




\begin{tabular}{|l|c|c|c|c|}
\hline Journal of Discrete Algorithms & 12.17 & 19 & 8.79 & 6.33 \\
\hline $\begin{array}{l}\text { Journal of Information Hiding and Multimedia Signal } \\
\text { Processing }\end{array}$ & 14.46 & 14 & 15.93 & 4.67 \\
\hline Robotics and Autonomous Systems & 30.61 & 70 & 14.39 & 23.33 \\
\hline IEEE Software & 20.81 & 72 & 7.01 & 24 \\
\hline International Journal of Sensor Networks & 19.34 & 20 & 19.7 & 6.67 \\
\hline
\end{tabular}

Table 4: Dataset-3 with parameters and index values.

\begin{tabular}{|c|c|c|c|c|}
\hline Title & e index & H index & A index & m index \\
\hline Archives of Computational Methods in Engineering & 16.73 & 32 & 9.75 & 10.67 \\
\hline MIS Quarterly: Management Information Systems & 40.48 & 132 & 13.42 & 44 \\
\hline $\begin{array}{l}\text { Proceedings of the Annual ACM Symposium on } \\
\text { Theory of Computing }\end{array}$ & 26.4 & 40 & 18.43 & 13.33 \\
\hline $\begin{array}{l}\text { Proceedings - Annual IEEE Symposium on } \\
\text { Foundations of Computer Science, FOCS }\end{array}$ & 24.56 & 62 & 10.73 & 20.67 \\
\hline IEEE Wireless Communications & 39.94 & 98 & 17.28 & 32.67 \\
\hline IEEE Transactions on Information Theory & 79.71 & 192 & 34.09 & 64 \\
\hline Journal of the ACM & 17.55 & 88 & 4.5 & 29.33 \\
\hline IEEE Journal on Selected Areas in Communications & 54.24 & 165 & 18.83 & 55 \\
\hline IEEE Communications Magazine & 68.36 & 144 & 33.45 & 48 \\
\hline Journal of Strategic Information Systems & 16.85 & 50 & 6.68 & 16.67 \\
\hline IEEE Transactions on Wireless Communications & 76.86 & 118 & 51.06 & 39.33 \\
\hline Foundations and Trends in Information Retrieval & 8.83 & 15 & 6.2 & 5 \\
\hline IEEE Transactions on Industrial Informatics & 46.71 & 39 & 56.95 & 13 \\
\hline Information Sciences & 77.68 & 91 & 67.31 & 30.33 \\
\hline Information and Organization & 10.2 & 34 & 4.06 & 11.33 \\
\hline Annual Review of Information Science and Technology & 6.86 & 38 & 2.24 & 12.67 \\
\hline Web Semantics & 19.7 & 49 & 8.92 & 16.33 \\
\hline $\begin{array}{l}\text { Proceedings - International Symposium on Computer } \\
\text { Architecture }\end{array}$ & 25.22 & 50 & 13.72 & 16.67 \\
\hline IEEE/ACM Transactions on Networking & 39.59 & 124 & 13.64 & 41.33 \\
\hline Enterprise Information Systems & 18.17 & 21 & 16.71 & 7 \\
\hline Journal of Management Information Systems & 18.84 & 90 & 4.94 & 30 \\
\hline Journal of Computer-Mediated Communication & 14.07 & 64 & 4.09 & 21.33 \\
\hline Communications of the ACM & 53.14 & 131 & 22.56 & 43.67 \\
\hline Decision Support Systems & 38.91 & 76 & 20.92 & 25.33 \\
\hline Information Systems Journal & 13.3 & 52 & 4.4 & 17.33 \\
\hline IEEE Network & 26.36 & 80 & 9.69 & 26.67 \\
\hline $\begin{array}{l}\text { Journal of the American Society for Information } \\
\text { Science and Technology }\end{array}$ & 42.24 & 83 & 22.49 & 27.67 \\
\hline Journal of Information Technology & 14.87 & 43 & 6.14 & 14.33 \\
\hline Journal of the Association of Information Systems & 17.32 & 31 & 10.68 & 10.33 \\
\hline Knowledge and Information Systems & 29.51 & 31 & 29.1 & 10.33 \\
\hline ACM Transactions on the Web & 15.13 & 26 & 9.81 & 8.67 \\
\hline Information Systems & 23.3 & 53 & 11.25 & 17.67 \\
\hline European Journal of Information Systems & 19.24 & 58 & 7.38 & 19.33 \\
\hline $\begin{array}{l}\text { ACM Transactions on Programming Languages and } \\
\text { Systems }\end{array}$ & 9.85 & 51 & 2.9 & 17 \\
\hline IEEE Communications Letters & 54.17 & 96 & 31.56 & 32 \\
\hline
\end{tabular}




\begin{tabular}{|l|c|c|c|c|}
\hline IEEE Transactions on Services Computing & 21.54 & 27 & 18.19 & 9 \\
\hline Information and Software Technology & 29.34 & 54 & 16.94 & 18 \\
\hline Software and Systems Modeling & 14.35 & 28 & 8.36 & 9.33 \\
\hline IEEE Internet Computing & 27.02 & 79 & 10.24 & 26.33 \\
\hline Information and Computation & 15 & 50 & 5.5 & 16.67 \\
\hline Soft Computing & 30.25 & 36 & 26.42 & 12 \\
\hline Interacting with Computers & 19.34 & 47 & 8.96 & 15.67 \\
\hline International Journal of Human Computer Studies & 20.71 & 76 & 6.64 & 25.33 \\
\hline Journal of Computer Security & 11.96 & 40 & 4.58 & 13.33 \\
\hline Journal of Educational Computing Research & 11.45 & 35 & 4.74 & 11.67 \\
\hline Computers and Security & 21.31 & 51 & 9.9 & 17 \\
\hline
\end{tabular}

\section{CONCLUSION}

Progressive increase in the scientific methods of journal citation witnessed the recent revolution of journal publishers intending to showcase their journal quality metrics. The dataset considered in clustering is based on few objectives that the bibliometric indices of computer science journals are of prime importance in evaluating the quality of a particular journal and the grouping of journal data is dependent on index values. The outcome of modified $\mathrm{k}$-means algorithm on a dataset of 150 journals resulted in 3 clusters $(k=3)$. Quality of cluster validations is within the limits. Further, work is in progress to study the influence of parameters on journal metrics.

\section{REFERENCES}

[1] M. Amin \& M. Mabe. 2000. Impact Factors: Use \& Abuse, Perspectives in Publishing, Vol.No. 1, 1-6.

[2] Garfield, E.1996. How can impact factors be improved? British Medical Journal, 313, 411-413.

[3] Glänzel, W., \& Moed, H. F. 2002. Journal impact measures in bibliometric research. Scientometrics, 53(2), 171-194.

[4] Saha, S., Saint, S. \& Christakis, D.A. 2003. Impact factor: a valid measure of journal quality? Journal of the Medical Library Association 91:42-46.

[5] Dong, P., Loh, M. \& Mondry, A. 2005. The "impact factor" revisited. Biomedical Digital Libraries 2:7 doi:10.1186/1742-5581-2-7.

[6] Lim, A., Ma, H., Wen, Q., Xu, Z., Cheang, B., Tan, B. \& Zhu, W. 2007. Journal-Ranking.com: An Online Interactive Journal Ranking System. Proceedings of the National Conference on Artificial Intelligence, Vol.22 (2):1723-1729.

[7] Hirsch, J.E. 2005. An index to quantify an individual's scientific research output. Proceedings of the National Academy of Sciences, Vol.102:16569-16572.

[8] Olden, J.D. 2007. How do ecological journals stack-up? Ranking of scientific quality according to the h-index. Ecoscience, Vol. 14(3):370-376.
[9] Rousseau, R. 2007. The influence of missing publications on the Hirsch index. Journal of Informetrics, Vol. 1:2-7.

[10] Vanclay, J.K. 2007. On the robustness of the h-index. Journal of the American Society for Information Science and Technology,Vol. 58(10):1547-1550.

[11] Steven B. Bird.2008. Journal Impact Factors, h Indices, and Citation Analyses in Toxicology. JOURNAL OF MEDICAL TOXICOLOGY, Vol. 4(4): 261-274.

[12] Egghe, L. 2006. Theory and practice of the g-index. Scientometrics, Vol. 69(1), .131-152.

[13] Kosmulski, M. 2006. A new Hirsch-type index saves time and works equally well as the original h-index. ISSI Newsletter, Vol. 2(3), 4-6.

[14] Rousseau, R. 2007. The influence of missing publications on the Hirsch index. Journal of Informetrics, Vol.1(1), 2-7.

[15] Jin, B. 2007. The AR-index: complementing the h-index. ISSI Newsletter, Vol.3(1), 6.

[16] Bornmann, L., Mutz, R., \& Daniel, H. 2008. Are there better indices for evaluation purposes than the h-index? A comparison of nine different variants of the h-index using data from biomedicine. Journal of the American Society for Information Science and Technology, Vol.59(5), 830-837.

[17] Steven B. Bird.2008. Journal Impact Factors, h Indices, and Citation Analyses in Toxicology. JOURNAL OF MEDICAL TOXICOLOGY, Vol.4(4): 261-274.

[18] http://www.elsevier.com/

[19] http://www.python.org

[20] Jonathan Baarsch and M. Emre Celebi.2012."Investigation of Internal Validity Measures for K-Means Clustering" in Proceedings of the International Multiconference of Engineers and Computer Scientists, Vol 1, IMCES, HongKong. 